\title{
Creencias de autoeficacia y contextos de evaluación. Un estudio con estudiantes universitarios
}

Self-efficacy beliefs and evaluation contexts. An study with university students

\author{
Volumen 17, Número 2 \\ Enero-Abril \\ pp. 1-32
}

Este número se publica el $1^{\circ}$ de mayo de 2017

DOI: http://dx.doi.org/10.15517/aie.v17i1.28144

\author{
Vanesa Analí Bonetto \\ Paola Verónica Paoloni \\ Danilo Silvio Donolo
}

Revista indizada en REDALYC, $\underline{\text { SCIELO }}$

Revista distribuida en las bases de datos:

LATINDEX, DOAJ, REDIB, IRESIE, CLASE, DIALNET, SHERPA/ROMEO, QUALIS-CAPES, MIAR

Revista registrada en los directorios:

ULRICH'S, REDIE, RINACE, OEI, MAESTROTECA, PREAL, CLACSO 


\title{
Creencias de autoeficacia y contextos de evaluación. Un estudio con estudiantes universitarios
}

\author{
Self-efficacy beliefs and evaluation contexts. An study with university students
}

\author{
Vanesa Analí Bonetto ${ }^{1}$ \\ Paola Verónica Paoloni ${ }^{2}$ \\ Danilo Silvio Donolo ${ }^{3}$
}

\begin{abstract}
Resumen: Este artículo presenta un estudio con el objetivo principal de contribuir al conocimiento del modo en que las creencias de autoeficacia se vinculan con las situaciones de evaluación en las que habitualmente se desempeña un grupo de estudiantes universitarios. Se trabajó con 133 estudiantes de carreras de grado de una universidad pública de Córdoba (Argentina). Se hizo un abordaje metodológico mixto, utilizando: los cuestionarios Multidimensional Scales of Perceived Self-efficacy de Bandura, Motivated Strategies Learning Questionnaire y un Cuestionario Ad-hoc sobre percepciones y valoración del contexto; observaciones de instancias de evaluación; calificaciones obtenidas por el alumnado y consignas de evaluación solicitadas. Se obtuvo como resultados, estudiantes con buen perfil motivacional y confianza en sus capacidades para el desempeño. Además, se observó dos tipos de contextos evaluativos, tareas de alcances amplios y parciales tradicionales, con diferencias en: creencias de autoeficacia de alumnos y alumnas, sus valoraciones y percepciones al respecto, feedback (retroalimentación) desplegado, rendimiento académico obtenido, espacio para el despliegue de autonomía, etc. De igual forma, se identificaron percepciones negativas de alumnos y alumnas sobre los parciales y positivas sobre las tareas de alcances amplios. Como conclusión, los contextos de evaluación influyen sobre las creencias de autoeficacia y el rendimiento académico de alumnos y alumnas y viceversa. Futuras investigaciones podrían orientarse hacia las vinculaciones entre la autoeficacia y la construcción de los criterios de evaluación, y/o la claridad de las consignas de evaluación.
\end{abstract}

Palabras clave: evaluación de la educación, creencias de autoeficacia, estudiantes universitarios, Argentina

Abstract: This article presents a study with the primary objective of contributing to knowledge of how self-efficacy beliefs are linked to assessment situations where usually a group of college students play. We work with 133 students of undergraduate public university of Cordoba (Argentina). We did a mixed methodological approach, using: questionnaires Multidimensional Scales of Perceived Self-efficacy Bandura, Motivated Strategies Learning Questionnaire and ad-hoc questionnaire on perceptions and appreciation of context; observations of instances of evaluation; grades obtained by students and slogans evaluation requested them. Results: Students with good motivational profile and confidence in their abilities to perform; we also observed two types of evaluative contexts, tasks partial reaches large and traditional, with differences in: self-efficacy beliefs of students, their assessments and perceptions about, deployed feedback, obtained academic performance, space for the deployment of autonomy, etc.; In the same way were identified negative perceptions of students on partial and positive about the tasks identified broad scope. Conclusion: evaluation contexts influence self-efficacy beliefs and academic performance of students and vice versa. Future research could be directed to the links between self-efficacy and: the construction of the evaluation criteria, and/or clarity of slogans evaluation.

Key words: educational evaluation, self-efficacy beliefs, university students, Argentina

\footnotetext{
${ }^{1}$ Aspirante a la beca Posdoctoral de CONICET. Doctora en Psicología por la Universidad Nacional de San Luis, Argentina. Dirección electrónica: $\underline{v}$.a.b 84@hotmail.com

2 Investigadora Adjunta del CONICET y docente en la Universidad Nacional de Río Cuarto, Argentina. Doctora en Psicología egresada de la Universidad Nacional de San Luis. Dirección electrónica: paopaoloni17@hotmail.com

3 Profesor consulto de la Universidad Nacional de Río Cuarto, Argentina. Investigador Principal de Conicet. Docente de carreras de posgrado en la Universidad Nacional del Comahue. Doctor en Ciencias de la Educación. Dirección electrónica: donolo@gmail.com
}

Artículo recibido: 21 de junio, 2016

Enviado a corrección: 19 de octubre, 2016

Aprobado: 23 de enero, 2017 


\section{Introducción}

Desde la perspectiva de Bandura (1994), la autoeficacia se entiende como las creencias de la gente sobre su capacidad para producir cierto rendimiento de manera exitosa.

Las creencias de autoeficacia que poseen los estudiantes y las estudiantes, conforman una variable motivacional de reconocida importancia en el marco de la literatura específica. En tal sentido, ejercen sobre los procesos de aprendizaje y el rendimiento académico obtenido una influencia poderosa -Bandura, 1987, 1999, 2005; Pajares y Schunk, 2001; Ruiz Dodobara, 2005; Taymal Ortega, 2008; entre otros-. No obstante esta premisa, una revisión de antecedentes sugiere que hay pocos trabajos que se hayan dedicado a estudiar la vinculación específica entre las creencias de autoeficacia en estudiantes y los rasgos de los contextos genuinos de evaluación que se promueven en el ámbito universitario.

Alonso Tapia (2000) advierte que la forma en que el alumnado es evaluado y el modo en que los resultados le son comunicados conforman un factor contextual de gran influencia en la motivación para sus aprendizajes. Sin embargo, a pesar de los avances logrados en los estudios sobre evaluación, todavía en muchas oportunidades la tendencia se orienta a valorar solo los resultados de los aprendizajes de los alumnos y las alumnas (Mateo, 2000) así como a mantener una concepción de evaluación restringida a un momento, ubicada al final del proceso de enseñanza y de aprendizaje (Camilloni, Celman, Litwin y Palou de Maté, 1998).

De acuerdo con lo expuesto, en este artículo se presenta parte de un trabajo de investigación ${ }^{4}$ que como objeto de estudio se focaliza principalmente en el contexto de evaluación y en los rasgos que más influyen en las percepciones de autoeficacia sustentadas por estudiantes.

Así, el objetivo principal fue contribuir con el conocimiento del modo en que las creencias de autoeficacia se vinculan con las situaciones de evaluación en las cuales habitualmente se desempeña un grupo de estudiantes universitarios. Específicamente se tuvo como objetivos: describir diferencias individuales de estudiantes universitarios con respecto a sus creencias de autoeficacia; analizar las características de los contextos de evaluación y procesos de feedback propuestos a los alumnos y las alumnas; conocer las percepciones $y$ valoraciones de estudiantes con respecto a las evaluaciones que realizan $y$

\footnotetext{
4 Trabajo de investigación de la licenciada Bonetto Vanesa Analía, presentado para optar por el grado de doctor en Psicología en la Universidad Nacional de San Luis, titulado: "Creencias de autoeficacia en estudiantes universitarios. Vinculaciones con contextos de evaluación".
} 
de los resultados que obtienen; profundizar en las relaciones entre creencias de autoeficacia, características del contexto de evaluación y resultados académicos obtenidos.

Si bien las creencias de autoeficacia cuentan con un amplio desarrollo empírico y conceptual, en nuestro país en particular, la mayoría de los estudios sobre este tema, privilegian una perspectiva exclusivamente cuantitativa -Cupani y Pérez, 2006; Olaz, 2001; Pérez y Cupani, 2008; entre otros-.Sin desconocer los aportes que estos trabajos efectúan al estado del arte, entendemos que, en general, dejan algo de lado las particularidades del contexto y de los matices que distinguen las relaciones establecidas entre persona y situación. Por esto, nosotros intentamos integrar análisis cuantitativos y cualitativos que posibiliten una comprensión más profunda del dinamismo que supone nuestro particular objeto de estudio.

\section{Referentes teóricos}

La autoeficacia tiene su origen en la teoría cognitiva-social de Bandura (1987, 1994). La teoría cognitiva-social, es una de las teorías del funcionamiento humano que destaca la importancia del medio social como condicionante para el funcionamiento, actitudes y creencias de la persona (Zimmerman y Cleary, 2006). En otras palabras, Bandura (1987) postula que los logros humanos dependerán de las interacciones entre el propio comportamiento, los factores personales y las condiciones ambientales. En el marco de esta teoría:

La autoeficacia percibida se define como los juicios de cada individuo sobre sus capacidades, en base a los cuales organizará y ejecutará sus actos de modo que le permitan alcanzar el rendimiento deseado (...) es un juicio emitido sobre la propia capacidad para alcanzar un cierto nivel de ejecución. (Bandura, 1987, p. 416)

Estos juicios de autoeficacia son un buen predictor de la conducta, del cambio de comportamiento y del nivel de logro que alcanzan las personas (Bandura, 1987, 1999, 2005; Pajares, 2001, 2002; Pajares y Schunk, 2001). Es decir, al actuar como un filtro entre los logros anteriores o habilidades y la conducta posterior, las creencias que las personas tengan acerca de sus capacidades, ampliarán su potencial para predecir la conducta posterior y su nivel de habilidad real. (Bandura 1987; Taymal Ortega, 2008)

Concretamente, las creencias de autoeficacia ayudan a determinar la cantidad de esfuerzo que los sujetos invierten en una actividad, cuánto tiempo van a perseverar a la hora de afrontar los obstáculos y, lo resistentes que estarán frente a situaciones adversas 
(Pajares y Schunk, 2001; Schunk, 1984). Así, se supone que los sujetos que se perciben como incapaces para alcanzar un nivel de logro requerido, disminuyen sus esfuerzos y creencias sobre los resultados que podrían comportarles tales logros (Bandura, 1987; Pajares, 2001).

Desde esta perspectiva en que la autoeficacia afecta el comportamiento, el rendimiento académico sería -entre otros aspectos- el resultado de lo que alumnos y/o alumnas "creen" que pueden lograr; estas creencias explicarían porqué el rendimiento puede variar entre alumnos aún con capacidades similares (Pajares, 2001, 2002). De esta manera, cómo se comporta la gente, a veces puede predecirse mejor por las creencias en sus capacidades que por lo que en realidad son capaces de lograr (Pajares, 2002).

Otro aspecto por considerar sobre las creencias de autoeficacia es su permeabilidad y maleabilidad, en el sentido que: pueden modificarse a partir de experiencias importantes. Así, experiencias de éxito en el desempeño de una tarea de logro impactarían en un incremento de la percepción de autoeficacia del sujeto (Bandura, 1987, 1999). De esta manera, las creencias de autoeficacia no son estáticas, sino que tienen la posibilidad de ser desarrolladas para favorecer el desempeño.

Entre las variaciones contextuales a las que son susceptibles las creencias de autoeficacia, la experiencia de enseñanza constituye un aspecto de vital importancia. Las instituciones educativas como contextos de logro suponen influencias potenciales sobre la autoeficacia de alumnos y alumnas, en relación con la modalidad de instrucción, la concepción de aprendizaje que se privilegie, la calidad de los procesos de feedback sobre el desempeño que se desplieguen, los rasgos de las prácticas de evaluación que se propongan, etc. (Pajares, 2002; Pajares y Schunk, 2001; Schunk y Meece, 2005). Ya en la década del ochenta, Schunk (1984) advertía que aquellas prácticas educativas que se enfocan en transmitir a los alumnos y las alumnas que son capaces y que deben mantener la motivación en la tarea para obtener resultados promisorios, dan lugar al aumento de la autoeficacia y habilidades de estos, por sobre aquellas prácticas que ofrecen información ambigua sobre las capacidades requeridas, o incluso transmiten información negativa en el sentido que no son especialmente hábiles para las tareas solicitadas. En un sentido similar pero dos décadas después, Greene (2004) sostiene que estudiantes que perciben que las clases apoyan su autonomía y que las evaluaciones están orientadas al aprendizaje más que a la competencia, expresan niveles más altos de autoeficacia.

Por lo expuesto hasta aquí, se vislumbró la necesidad de repensar los contextos de aprendizaje y evaluación que se propician en el ámbito universitario, para focalizar el 
fortalecimiento de creencias positivas de autoeficacia a través de las cuales el estudiantado pueda también interpretar y crear contextos de aprendizaje beneficiosos para su motivación y rendimiento.

\section{Contextos de evaluación. Vinculación con creencias de autoeficacia}

El contexto de evaluación constituye una dimensión clave del proceso de enseñanza y de aprendizaje, la evaluación en sí es una herramienta didáctica que permite valorar los aprendizajes logrados por estudiantes, al tiempo que provee información importante a docentes para reorientar la actividad académica (Ruiz de Pinto, 2002; Villardón Gallego, 2006).

Las siguientes citas se orientan en el sentido de que lo que entendemos podría ser una definición de evaluación desde nuestra perspectiva:

(...) desde una perspectiva didáctica, el concepto implica juzgar el aprendizaje y juzgar la enseñanza, atribuirles un valor a los actos y las prácticas de los docentes y atribuirles un valor a los actos que dan cuenta de los procesos de aprendizaje de los estudiantes. (Litwin, 1998, p. 13)

(...) la evaluación como una poderosa herramienta para desarrollar competencias valiosas en los estudiantes, así como para mejorar el nivel de implicación y motivación de los mismos, apostando por la participación y por el protagonismo del alumnado en su propia evaluación. (Ibarra, Rodríguez y Gómez, 2012, p. 209)

Los nuevos desarrollos sobre evaluación se vinculan a un tipo de evaluación alternativa -resolución de problemas, portafolios, evaluación dinámica, tareas de alcances amplios-, incorporada en los sistemas educativos en los últimos años, que permite facilitar el monitoreo del avance del trabajo en estudiantes. En esta nueva concepción de evaluación, se incorporan aspectos desatendidos en la evaluación tradicional y, lo que es más importante de acuerdo con el problema de estudio, se empiezan a identificar los vínculos entre las características de las evaluaciones y los procesos psicológicos inherentes a la construcción de los aprendizajes (Coll, Rochera Villach, Mayordomo Saíz y Naranjo Llanos, 2007; González Pérez, 2000; Hamayan 1995, en López Frías e Hinojosa Kleen, 2000; Mateo, 2000).

Pese a estos nuevos desarrollos, muchas veces en la universidad los alumnos y las alumnas todavía acreditan los conocimientos respondiendo a formas limitadas de evaluación, que restringen sus modos de comunicar lo que saben. En general, la evaluación en la 
universidad se realiza para medir la cantidad de información que ha archivado el estudiantado en su memoria, "se demanda en la evaluación una gran dosis de memorización más que de reflexión" (González Pérez, 2000, p. 40). De esta manera, el alumno o la alumna, fracasa cuando no estudia para la evaluación del modo en que se espera que aprenda, cuando no memoriza, cuando no resuelve algún ejercicio del texto que presentó el docente. El sentido de la evaluación suele centrarse en lo estrictamente cognitivo, contenidos aislados que no están conectados con las experiencias y saberes previos de los sujetos y que dejan de lado el significado que le atribuyen a los conocimientos construidos (González Pérez, 2000; López Frías e Hinojosa Kleen, 2000; Monereo y Pozo, 2003).

Existe entonces la necesidad de replantear el concepto de evaluación y de reflexionar sobre los modos de evaluar en la universidad y su relación con la concepción que se tiene acerca del aprendizaje y de la enseñanza. Parece lícito preguntarse en qué contextos son eficaces o pertinentes los diferentes métodos evaluativos, en qué contextos son eficaces los nuevos métodos de evaluación que han surgido y, cómo se puede mejorar el proceso educativo integral incluyendo a la evaluación como instancia estructurante (Álvarez Méndez, 2000; Bloom, Hastings y Madaus, 1975; Coll et al., 2007; Camilloni et al., 1998).

Comprendemos a la evaluación como un proceso amplio que integra también momentos anteriores y posteriores a la instancia misma de evaluación. Coll y Onrubia (2002) plantean al respecto un interesante aporte sobre un conjunto de momentos que para ellos conforman el proceso general de evaluación, a saber: preparación (actividades que se realizan en el aula para preparar la participación del alumno o de la alumna en la situación de evaluación), evaluación (actividades que el alumno o la alumna debe resolver como evaluación propiamente dicha), corrección (juicio de valor sobre la participación del alumno o de la alumna en la evaluación), devolución (actividades en las que se le devuelve al alumno o la alumna un resultado, fruto de la corrección de su participación en la evaluación) y aprovechamiento (actividades que se realizan en torno a algún aspecto que pretendía cubrir la situación de evaluación).

Entre estos momentos de la evaluación, el de devolución o los procesos de feedback merecen ser destacados por su importancia, dado que los resultados de evaluaciones que "vuelven" a los alumnos y las alumnas con los aportes del profesor o profesora permiten continuidad en las actividades de aprendizaje y de enseñanza, porque dan cuenta de las posibilidades de aprender, tanto del cuerpo docente, en lo que respecta a que encuentra oportunidades para el mejoramiento de sus respectivas propuestas pedagógicas, como del alumnado, al favorecer el desarrollo de sus desempeños académicos y producciones 
consecuentes (Camilloni et al., 1998; Rodríguez Conde y Jiménez Corrales, 2010; Rochera Villach y Naranjo Llanos, 2007).

Rinaudo y Paoloni (2013) y Paoloni y Rinaudo (2014) proponen interesantes planteos acerca del feedback que intentan ampliar el modelo propuesto Hattie y Timperley (2007) al respecto. Se trata de cinco dimensiones de feedback, las primeras cuatro retomadas de los autores de referencia y la quinta propuesta como un modo de complementar la teoría original. Las dimensiones referidas son las siguientes: feedback referente a la tarea, que incluye información referente a cuán bien se ha realizado una tarea (por ejemplo: precisión de una respuesta). El feedback al proceso entiende al aprendizaje como una construcción de significado y se orienta a mejorar los procesos cognitivos o procedimientos necesarios para avanzar en la realización de una tarea. El feedback referido a las estrategias de autorregulación que se desarrollan para llevar a cabo la tarea supone procesos de dialogo en torno a la manera en que el estudiantado monitorea, dirige y regula aspectos cognitivos y motivacionales implicados en sus aprendizajes. El feedback referido a la persona involucra juicios sobre el estudiante o la estudiante, no directamente vinculados con una tarea académica pero que de un modo u otro tienen el potencial de influir en el desempeño académico: "que inteligente que sos", "que capaz que sos". Por último, el feedback en relación con percepciones sobre el contexto implica: una dimensión próxima en el tiempo y otra dimensión proyectada a futuro; la primera involucra expectativas iniciales de estudiantes sobre aspectos del contexto académico inmediato (los contenidos que involucrará la asignatura, características que tendrán las evaluaciones, etc.); la segunda implica aspectos en relación con el rol profesional: con quién trabaja un profesional graduado o graduada de la carrera que cursan, qué tipo de actividades están habilitados para realizar, etc. (Paoloni y Rinaudo, 2014).

De acuerdo con lo expuesto, en este trabajo se destaca la importancia que reviste el hecho de que la evaluación se convierta en un contexto poderoso para el aprendizaje de estudiantes, es decir, que brinde oportunidades para que alumnos y alumnas, puedan realizar actividades que promuevan tanto aprendizajes genuinos como desarrollo personal (Rinaudo, 2014).

\section{Metodología}

Se adopta un encuadre metodológico mixto que integra enfoques cualitativos y cuantitativos en una misma investigación; ya que ambos conjuntamente no se excluyen sino que enriquecen la investigación (Creswell y Plano Clark, 2007; Sampieri, Collado y Lucio, 
2006). De esta manera, se trabajó con métodos variados de recolección de datos, a saber, desde una perspectiva cualitativa: observaciones y registro en audio de instancias de evaluación, análisis de documentos (específicamente los protocolos o consignas de evaluación que se le presentaron a los alumnos y a las alumnas), y entrevistas semiestructuradas a estudiantes. Mientras que, desde una perspectiva con una orientación más cuantitativa, se contemplaron los análisis de los datos obtenidos mediante los cuestionarios: MSPSE, MSLQ y un cuestionario ad hoc sobre percepciones del contexto y autoeficacia.

\subsection{Participantes}

Durante 2010 y 2011, se trabajó con 133 estudiantes avanzados de carreras de grado, correspondientes a una universidad pública de la provincia de Córdoba. Específicamente, participó la totalidad del alumnado que cursó las siguientes asignaturas: Didáctica ( $\mathrm{N}=9)$ Facultad de Ciencias Exactas Físico-Químicas y Naturales-; Psicología Educacional (N=51) Facultades de Ciencias Humanas y Ciencias Exactas Físico-Químicas y Naturales-; Tráfico (N=13) -Facultad de Ingeniería-; Didáctica I $(\mathrm{N}=17)$ y Didáctica II ( $\mathrm{N}=43)$-Facultad de Ciencias Humanas-. En promedio, la edad de los alumnos y de las alumnas de esta muestra era de 22 años; siendo del sexo femenino, un $72.18 \%$ de ellos y, del sexo masculino, un $27.81 \%$.

Los estudiantes y las estudiantes con los que trabajamos conformaban una muestra incidental, respondiendo a ciertos criterios, a saber: realizaban carreras universitarias de grado, tanto de educación como de otras áreas y, además eran alumnos avanzados de dichas carreras (cursaban el penúltimo año de la carrera); en otras palabras, alumnos que formaban parte del ámbito universitario y participaban habitualmente de los contextos de enseñanza aprendizaje y/o evaluación que allí se promueven.

\subsection{Instrumentos y modalidades de recolección de datos}

Los criterios de selección de los instrumentos y modalidades de recolección de datos tuvieron en cuenta los objetivos que se propusieron para este estudio y además las cualidades técnicas de los instrumentos utilizados. Así, estos instrumentos y modalidades de recolección de datos ofrecieron información referida a: percepciones de autoeficacia y orientaciones motivacionales básicas que guiaban los aprendizajes de estudiantes (instrumentos MSPSE, MSLQe); características que definían las instancias de evaluación y los procesos de feedback desplegados al respecto (mediante observaciones de instancias de evaluación y análisis de protocolos de las evaluaciones propiamente dichas); rendimiento 
académico obtenido por los estudiantes y las estudiantes (a través de las calificaciones obtenidas en cada una de las instancias de evaluación en las que participaron); percepciones del alumado sobre evaluaciones tradicionales y alternativas (mediante el cuestionario ad hoc). Las entrevistas semi-estructuradas, permitieron ampliar la información referida a las percepciones de alumnos sobre estos aspectos.

\subsubsection{Multidimensional Scales of Perceived Self-efficacy (MSPSE)}

El MSPSE -Bandura (1990), en la versión traducida y adaptada al español por Carrasco y del Barrio (2002)- es un cuestionario de autoinforme que consta de 35 ítems que se responden con base en una escala Likert de 5 puntos, a través de la cual los sujetos expresan sus respuestas: desde "fatal" para el numero 1, "no muy bien" para los números 2 y 3, "bien" para el número 4 y "fenomenal" para el número 5. De esta manera, al igual que en la versión original, los puntajes altos de los alumnos y alumnas indicarán una alta creencia de autoeficacia, así como los puntajes bajos indicarán baja autoeficacia. El análisis de las respuestas, arroja un factorial de tres dimensiones de autoeficacia: académica, social y autorregulatoria. La autoeficacia académica evalúa la capacidad percibida por el sujeto para dirigir su propio aprendizaje, así como expectativas personales parentales o del profesorado puestas en su persona. La autoeficacia social considera la capacidad percibida para las relaciones entre iguales y para actividades de ocio. La autoeficacia autorregulatoria refiere a la capacidad del sujeto para resistirse a los iguales ante la involucración en actividades de riesgo, relacionadas con transgresión de normas ${ }^{5}$.

Este instrumento, se administró durante el año 2011 a estudiantes que cursaban Didáctica I y /I $(\mathrm{N}=44)$ y, a estudiantes que cursaban Tráfico $(\mathrm{N}=10)^{6}$. Sobre esta versión del MSPSE traducida al español y adaptada por Carrasco y del Barrio (2002), se realizó para su administración, una modificación previamente consultada con los autores en cuestión, que no afectaba a la estructura ni al sentido del instrumento, tal como algunas expresiones idiomáticas típicas de donde proviene.

Además, es interesante aclarar que esta versión validada al español por Carrasco y del Barrio (2002), muestra, una adecuada fiabilidad y validez como medida de autoeficacia. La escala total de autoeficacia obtuvo un buen índice de fiabilidad, con un Alfa de Cronbach de 0.91. Por su parte, nuestro análisis confirma que el instrumento presenta adecuadas

\footnotetext{
${ }^{5}$ No se trabajó con la sub-escala autoeficacia autorregulatoria de este instrumento, debido a que consideramos que lo que esta mide no responde a los objetivos propuestos en el presente trabajo; es decir, no se orienta a medir la autorregulación del aprendizaje.

${ }^{6}$ Es interesante aclarar que para la toma de todos los cuestionarios, se trabajó con alumnos y alumnas que estuvieran presentes en la clase en el momento de la toma de los instrumentos.
} 
características de confiabilidad para el total de ítems, con un Alfa de Cronbach igual a 0,77 y, para las sub-escalas utilizadas: autoeficacia académica y autoeficacia social, un Alfa de Cronbach de 0,63 para la primera y un Alfa de Cronbach de 0,75 para la segunda.

\subsubsection{Motivated Strategies Learning Questionnaire (MSLQe)}

EI MSLQ (Pintrich, Smith, García y Mckeachie 1991, en la versión adaptada al español y validada por Donolo, Chiecher, Paoloni y Rinaudo, 2008 -MSLQe-) es un cuestionario de administración colectiva que consta de 81 ítems. Las respuestas a los ítems se dan con base en una escala Likert de 7 puntos en la que los sujetos marcan el grado de acuerdo 0 desacuerdo con las afirmaciones expresadas en cada uno de ellos; así pues, los valores más bajos son indicadores de poco acuerdo, en tanto que los más altos indican que lo expresado por el ítem representa al sujeto en buena o muy buena medida.

El cuestionario consta de dos secciones: una referida a motivación y la otra relativa al uso de estrategias de aprendizaje ${ }^{7}$. La sección de motivación está integrada por 31 ítems que conforman seis escalas relativas a distintos aspectos motivacionales; a saber: metas de orientación intrínseca, metas de orientación extrínseca, valoración de la tarea, creencias de autoeficacia, creencias de control del aprendizaje y ansiedad.

En total, el instrumento se administró a 125 alumnos y alumnas ${ }^{8}$ : durante el 2010 lo respondieron estudiantes de Psicología Educacional $(\mathrm{N}=49)$ y de Didáctica $(\mathrm{N}=9)$. En el 2011 lo respondieron estudiantes que cursaban Didáctica ly I/ $(\mathrm{N}=54)$ y de Tráfico $(\mathrm{N}=13)$.

Sobre esta versión del MSLQ adaptada por Donolo et al. (2008), la confiabilidad fue calculada mediante el alfa de Cronbach para ambas secciones del cuestionario; estos fueron de 0,76 para los 31 ítems que miden motivación y de 0,89 para los 50 ítems que miden uso de estrategias de aprendizaje. Para la validez, se utilizó la técnica de acuerdo entre jueces. Los resultados sugieren una confiabilidad aceptable para los ítems de cada una de las secciones del MSLQ y, los jueces han acordado en garantizar la validez del $94 \%$ de sus ítems. Por su parte, este análisis confirma que el instrumento presenta adecuadas características de confiabilidad para el total de ítems, con un alfa de Cronbach igual a 0,91, y para la sección motivación utilizada en este estudio: un alfa de Cronbach de 0,78.

\footnotetext{
7 Por una cuestión de extensión, no se incluye para este estudio la sección referida al uso de estrategias de aprendizaje.

${ }^{8}$ Igual a la aclaración del pie de página 6.
} 


\subsubsection{Cuestionario Ad hoc sobre percepciones y valoración del contexto}

Este cuestionario está compuesto por 9 preguntas; cuatro que indagan específicamente las percepciones del alumno o de la alumna sobre las evaluaciones tradicionales de la asignatura; otras cuatro preguntas que indagan específicamente las percepciones del alumno o de la alumna sobre una evaluación alternativa (tarea de alcances amplios); una pregunta que indaga sobre la preferencia de estos por la evaluación tradicional o alternativa. Concretamente, las primeras 8 preguntas se responden optando de manera no excluyente, marcando con una cruz en aquella o aquellas opciones que el alumno o la alumna considere que describen mejor sus percepciones con respecto a lo indicado. Por su parte, la pregunta número 9 , se divide en 6 sub-preguntas, englobando las respuestas entre tres opciones excluyentes que se mantienen constantes; a saber: evaluación tradicional, evaluación alternativa, no contesta. El alumno o la alumna identifica mediante un tilde, aquella opción por la cual se siente más representado.

Este cuestionario, fue administrado individualmente al alumnado de Psicología Educacional ( $\mathrm{N}=26)$ durante el año lectivo 2010.

\subsubsection{Observaciones de instancias de evaluación}

Se recurrió a observaciones no participantes y al registro en audio de la totalidad de las instancias de evaluación de las diferentes asignaturas mencionadas. Estas estuvieron orientadas por grillas elaboradas previamente con base en criterios teóricos -considerando los momentos de la evaluación planteados por Coll y Onrubia (2002) y las dimensiones de feedback, de Rinaudo y Paoloni (2013) y Paoloni y Rinaudo (2014)-.

De igual forma, se consideraron las observaciones de los contextos de evaluación destinada a indagar las características que definían estos contextos, así como los procesos de feedback desplegados al respecto. La grilla elaborada para ello se estructuraba en tres momentos del proceso de evaluación: antes, durante y después de la evaluación.

De esta forma se observaron, a lo largo de los años 2010 y 2011, todas las evaluaciones que se solicitaron a los alumnos y a las alumnas en cada una de estas asignaturas mencionadas, esto es 12 instancias de evaluación. Las instancias de evaluación están disgregadas en: 2 instancias de evaluación de la asignatura Didáctica, 3 de la asignatura Psicología Educacional, 3 en la asignatura Tráfico y 4 en la asignatura Didáctica I y II. Es pertinente aclarar que para observar estas instancias de evaluación se presenciaron todas las clases de cada una de las asignaturas, ya que se entiende como se mencionó, que 
la evaluación comprende momentos anteriores y posteriores al instante de evaluación propiamente dicha.

\subsubsection{Entrevistas semi-estructuradas}

Las preguntas para las entrevistas se focalizaron en torno a las creencias de autoeficacia de alumnos y alumnas con respecto a las instancias de evaluación de las que participaron, tanto en relación con sus trayectorias generales como estudiantes universitarios, como de acuerdo con las situaciones específicas de evaluación propuestas desde las cátedras que participaron en el estudio. Las pautas que focalizaban en instancias de evaluación propuestas desde las cátedras se organizaban en dos: pautas relativas a evaluaciones parciales tradicionales y pautas relativas a situaciones de evaluación alternativa. Ambas se estructuraban considerando los mismos tres momentos fundamentales que se integraban en las grillas de observación: antes, durante y después de cada situación de evaluación.

Se realizaron en total 33 entrevistas $^{9}: 9$ entre alumnos de Didáctica; 11 entre alumnos de Tráfico; 5 entre alumnos de Didáctica I y 8 entre alumnos de Didáctica II. Estas se efectuaron en horarios extra-clase al finalizar el desarrollo de cada asignatura, con una duración aproximada de 30 minutos. Se desarrollaron de manera grupal (grupos de 2 alumnos como mínimo y 4 alumnos como máximo), con análisis individuales de las respuestas. Fueron realizadas a sub-grupos de alumnos de cada asignatura -en el 2010 a alumnos de Didáctica y en el 2011 a alumnos de Tráfico y Didáctica / y II- conformados según la predisposición para participar y la disponibilidad en el momento (en cuanto a presencia en ese momento en la universidad o disponibilidad de tiempo). Solo un alumno de Tráfico se rehusó a participar en ellas.

\subsubsection{Análisis de protocolos de evaluación}

Se analizaron los documentos de evaluación (consignas) que los estudiantes y las estudiantes de las diferentes asignaturas debieron responder como requisito para regularizar o promocionar la materia. En total se analizaron 12 protocolos de evaluación: 2 de la asignatura Didáctica, 3 de la asignatura Psicología Educacional -respectivamente obtenidas en el 2010-, 3 de la asignatura Tráfico y 4 de las asignaturas Didáctica I y II -respectivamente obtenidos en el 2011 -

\footnotetext{
${ }^{9}$ Las entrevistas fueron realizadas a sub-grupos de alumnos y alumnas de cada asignatura, conformados según la predisposición para participar y la disponibilidad en el momento (en cuanto a presencia en ese momento en la universidad o disponibilidad de tiempo).
} 
Para el análisis, se remitió a categorías teóricas planteadas por diversos autores que fundamentaron este trabajo.

\subsubsection{Calificaciones}

Las calificaciones obtenidas por alumnos y alumnas en las distintas instancias de evaluación de cada asignatura fueron consideradas indicadores del rendimiento académico obtenido.

Se contó, entre el 2010 y el 2011, con las calificaciones de 133 alumnos. En el 2010: las calificaciones de 9 alumnos que cursaban Didáctica y de 51 alumnos que cursaban Psicología Educacional. En el 2011, las calificaciones de 13 alumnos que cursaban Tráfico, de 17 alumnos que hacían lo propio en Didáctica / y de 43 de Didáctica II. Con estas calificaciones, se realizó el cálculo de la media general para obtener el rendimiento de grupo y a su vez de la media de las calificaciones de cada contexto de evaluación, es decir, parcial y tarea de alcances amplios, para obtener el rendimiento del grupo en cada uno de estos contextos en particular. A su vez, con estos datos se obtuvo una media general de los alumnos y alumnas de todas estas asignaturas en conjunto, como así también diferenciando en cada contexto evaluativo (parcial y tarea de alcances amplios).

\section{Resultados}

Los resultados se organizan del siguiente modo: Aspectos motivacionales implicados en los aprendizajes; Rasgos contextuales que definían a los contextos de evaluación tradicional y alternativa; Percepciones de los alumnos y alumnas sobre estos contextos $y$ vinculación con la autoeficacia.

\subsection{Aspectos motivacionales implicados en los aprendizajes}

La mayoría de los alumnos y de las alumnas que participó en este estudio, independientemente de la asignatura que cursaban, tenía un buen perfil motivacional general. Concretamente, las creencias de autoeficacia fueron precisamente un aspecto importante. A continuación, la Tabla 1 muestra los valores hallados. 
Tabla 1.

Media y desviación estándar, para cada una de las escalas de motivación que integran el MSLQe.

\begin{tabular}{l|c|c|c|c|c|c|c|c}
\hline Dimensiones/ Alumnos & \multicolumn{2}{|c|}{$\begin{array}{c}\text { Alumnos de } \\
\text { Didáctica }\end{array}$} & \multicolumn{2}{c|}{$\begin{array}{c}\text { Alumnos de } \\
\text { Psicología } \\
\text { Educacional }\end{array}$} & \multicolumn{2}{c|}{$\begin{array}{c}\text { Alumnos de } \\
\text { Tráfico }\end{array}$} & \multicolumn{2}{c}{$\begin{array}{c}\text { Alumnos de } \\
\text { Didáctica I y II }\end{array}$} \\
\hline Dimensiones de motivación & $\boldsymbol{M}$ & $\boldsymbol{D}$. E. & $\boldsymbol{M}$ & $\boldsymbol{D}$. $\boldsymbol{E}$. & $\boldsymbol{M}$ & $\boldsymbol{D}$. E. & $\boldsymbol{M}$ & $\boldsymbol{D}$. E. \\
\hline Metas de orientación intrínseca & 5,30 & 0,70 & 5,06 & 1,18 & 5,44 & 0,86 & 5,40 & 0,75 \\
Metas de orientación extrínseca & 2,83 & 1,19 & 3,44 & 1,52 & 3,44 & 1,09 & 3,31 & 1,13 \\
Valoración de la tarea & 6,14 & 0,52 & 5,15 & 1,01 & 5,70 & 0,70 & 5,72 & 0,72 \\
Creencias de control & 4,94 & 0,90 & 5,08 & 1,22 & 5,36 & 0,91 & 5,08 & 0,83 \\
Creencias de autoeficacia & 5,77 & 0,47 & 5,29 & 0,95 & 5,71 & 0,65 & 5,35 & 0,72 \\
Ansiedad & 3,53 & 1,54 & 3,95 & 1,29 & 3,13 & 1,20 & 3,87 & 1,14 \\
Sección motivación en general & 5,00 & 0,38 & 4,66 & 0,65 & 4,80 & 0,46 & 4,79 & 0,52 \\
\hline
\end{tabular}

Nota: Datos para 125 alumnos y alumnas de: Psicología Educacional $(\mathrm{N}=49)$, Didáctica $(\mathrm{N}=9)$, Tráfico $(\mathrm{N}=13)$ y Didáctica I y II ( $\mathrm{N}=54)$; asignaturas pertenecientes a una universidad pública de la provincia de Córdoba. Año 2010 y 2011.

Los resultados obtenidos en el MSLQe sugieren que los alumnos y las alumnas estarían, en general, motivados para aprender en el marco de las asignaturas de referencia. Esto llama a reflexionar sobre aquel prejuicio que muchas veces se les atribuye injustamente a los alumnos y las alumnas, referido a que "no" están motivados. Teniendo este planteamiento como base, se reflexiona también sobre el hecho de que el hilo central de los desarrollos teóricos con los que se ha trabajado no se enfoca en que los alumnos y las alumnas no están motivados, más bien la preocupación se orienta hacia ver cómo desarrollar mejores condiciones para contribuir al desarrollo de una motivación orientada hacia metas de aprendizaje en estudiantes. Se sugiere entonces, que éste es el punto en el que se debe reorientar nuestra mirada: hacia la mejora, en vez de orientarla hacia remarcar aquello que no está, pues no es raro escuchar entre los allegados a la educación ${ }^{10}$ expresiones del tipo: "los estudiantes no tienen ganas de aprender", "los estudiantes no se motivan".

En lo referente específicamente a creencias de autoeficacia, otro grupo de resultados que se orientan a destacar coincidencias entre los diferentes grupos de estudiantes que participaron indican que, en general, los alumnos y las alumnas creían en sus capacidades para el desempeño, es decir, como se anticipó desde la teoría -Bong, 2004; González Fernández, 2005; Huertas, 1997; Pajares y Schunk, 2001; Paoloni, Rinaudo, Donolo y Chiecher, 2006; Ruiz Dodobara, 2005; entre otros- son alumnos que probablemente estarían más predispuestos a: proponerse metas más desafiantes e implicar mayor esfuerzo y

\footnotetext{
10 Se refiere a situaciones que suelen propiciarse entre las actitudes de docentes en el ámbito universitario en general, es decir, no se remite a la actitud de ningún docente en particular, así como tampoco se pretende desvalorizar la labor docente. Sin embargo, no se puede desconocer que son actitudes que a veces se presentan.
} 
persistencia hacia estas, implicar mayor interés y compromiso en las actividades, por lo tanto, obtener resultados de calidad en la tarea asumida, así como mayores posibilidades de realizar intervenciones para controlar el contexto. También, como se anticipaba, la autoeficacia alta predispone al sujeto a una mayor curiosidad y pasión por instruirse, una mayor persistencia en disciplinas universitarias difíciles, un mayor valor atribuido a las tareas $y$, en consecuencia, mayores posibilidades de obtener el éxito académico. Por otra parte, los logros obtenidos fortalecen en los sujetos su percepción de autoeficacia.

De acuerdo con lo expuesto, se considera que el aporte, en este sentido, se orienta a que se debe quizás reorientar o repensar ideas o prejuicios y empezar a "creer" en el alumno o la alumna, como un sujeto que siente confianza en sus capacidades para desempeñarse en los requerimientos del ámbito universitario, como un sujeto que está motivado para el aprendizaje. Entonces, los resultados de este estudio al respecto no deberían conducir hacia una respuesta acabada, sino que solo deberían ser el puntapié para empezar a interrogar sobre la labor en los contextos de enseñanza y de aprendizaje.

\subsection{Rasgos contextuales que definían a los contextos de evaluación tradicional y alternativa}

A continuación, la Tabla 2 describe algunos rasgos que caracterizaban a los contextos evaluativos observados. 
Tabla 2.

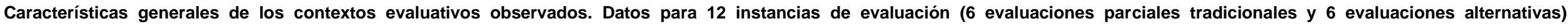
correspondientes a tres materias pedagógicas y a una ingenieril de una universidad pública de la provincia de Córdoba. Año 2010 y 2011.

\section{Características generales de los contextos evaluativos observados}

\section{Parcial tradicional}

\section{Evaluación alternativa: tarea de alcances amplios}

\begin{tabular}{lll}
\hline & Se daban a conocer los criterios y/o modalidades de evaluación excepto en el Estudio III. \\
Aspectos comunes & Se anticipaba el plazo previsto para la entrega del resultado requerido. \\
& Se comunicaban los contenidos por evaluar, así como los objetivos.
\end{tabular}

\section{Rendimiento académico} En general, tendencia a bajo.

En general, tendencia a alto.

Procesos de feedback Predominaron procesos de feedback relativos a la tarea entendida como producto.

Se desplegaron de modo equitativo, procesos de feedback relativos al proceso de elaboración de una tarea, en relación con la tarea como producto, feedback a las estrategias de aprendizaje, feedback relativo a percepciones sobre el contexto y feedback sobre aspectos de la persona.

\begin{tabular}{ll}
\hline Modalidad de resolución & Individual \\
\hline $\begin{array}{l}\text { Contexto de } \\
\text { desempeño }\end{array}$ & $\bullet \quad$ Contexto áulico \\
\hline $\begin{array}{l}\text { Espacio para el despliegue } \\
\text { de autonomía }\end{array}$ & $\begin{array}{l}\text { Reducido. Los alumnos y alumnas debían responder } \\
\text { preguntas pautadas, en las que los temas estaban definidos } \\
\text { de antemano. Contaban con libertad para decidir acerca de } \\
\text { los ejemplos por incluir como modo de responder a algunos } \\
\text { ítems. }\end{array}$
\end{tabular}

\section{Plazo establecido para la Dos horas}

entrega del resultado

Procesos cognitivos
implicados

\section{Promoción de procesos de Escasa}

autorregulación por parte de

los alumnos

\section{Grupal}

Contexto áulico y extra-aúlico

Percepción

instrumentalidad

de

significatividad

y Escasa a nula

Importante. Los alumnos y las alumnas contaban con espacio para el despliegue de diferentes tipos de autonomía: organizativa (posibilidades de elegir grupos de compañeros, horarios de trabajo, espacios de reuniones, etc.); procedimental (libertad para elegir los temas y materiales sobre los que trabajar y establecer las relaciones según sus intereses); cognitiva (promoción del pensamiento crítico, procesos de feedback generados sobre el desempeño de los alumnos, etc.).

Integración de la evaluación como parte del proceso de enseñanza y de aprendizaje 
Como se advierte en la Tabla 2, el rendimiento académico de los alumnos y las alumnas fue mejor en las tareas de alcances amplios $(M=7.61 ; D$. $E .=0,88)$, en comparación con los obtenidos en los parciales tradicionales ( $M=4,80$; D. $E .=1,27)$.

En las evaluaciones parciales predominaron los procesos de feedback relativos a la tarea entendida como producto. Es decir, en el contexto de las evaluaciones parciales se llevaron a cabo procesos de feedback, no obstante, de acuerdo con lo observado, eran prácticas muchas veces limitadas; por ejemplo, si bien los alumnos y las alumnas en todas las evaluaciones parciales en las que participaron -en total 6- contaban con la posibilidad de acceder a su parcial, de ver las correcciones y de dialogar acerca de su desempeño, en general esto quedaba muy ligado solo al resultado, a las calificaciones que habían obtenido. Al ser una evaluación donde para la entrega del resultado se establece un plazo corto, es decir, que requiere una resolución inmediata del alumnado, no brindaba mucho lugar para generar procesos de feedback a la elaboración de esa tarea; por ejemplo, se cree que, desde esta concepción tradicional de evaluación, no siempre -solo en 3 de 6 parciales- los docentes y/o las docentes, estaban abiertamente dispuestos a responder dudas, preguntas y orientar a alumnos mientras estos estaban realizando la evaluación propiamente dicha en el aula. En el mismo sentido, ocurre con las demás dimensiones de feedback.

Por su parte, en las tareas de alcances amplios -en adelante TAA- se desarrollaron, en general, buenas prácticas de feedback; precisamente en relación con las siguientes dimensiones:

Feedback al proceso de elaboración de una tarea: las TAA tenían una prórroga importante de tiempo para su elaboración, esto dio pie a la observación de procesos más ricos al respecto de esta dimensión de feedback, por ejemplo: en 5 de 6 instancias de evaluación, el cuerpo docente respondía más detenidamente dudas, preguntas y, orientaban a los alumnos y las alumnas durante la elaboración de las tareas. A continuación, un ejemplo en relación con las explicaciones y la orientación de las docentes de Didáctica / y II, sobre las consignas de las TAA de esta asignatura: 
Docente 1 - Para la gente de Psicopedagogía, la semana pasada les pasamos una hojita con algunas indicaciones para la tarea, no sé si ustedes ¿tienen alguna idea?, es una TAA (...) a modo de sugerirles algunas ideas, nosotras pensamos que el psicopedagogo podría estar pensando en algún contexto no formal (...) para definir un proyecto de trabajo. Entonces: ¿qué podríamos hacer en un proyecto de trabajo?, empecemos, por ejemplo para una guardería, la idea es que ustedes puedan tener un propósito, "¿qué quiero con estos materiales?", "con este material quiero a los niños de guardería facilitar el ingreso y la permanencia en la guardería", "¿qué voy a proponer?", "materiales, videos, actividades"; esas actividades: "¿cómo se pueden desarrollar?" y cuál es el fundamento, porque yo si voy a hablar de motivación: “¿qué cosas he estudiado de motivación?” (...) es decir, no es proponer lo primero que se les ocurra, tenemos que ver, si selecciono un material para la diversidad cultural: “¿por qué es importante la diversidad cultural?”, “¿qué aspectos, qué contenidos puedo tomar yo para fundamentar eso?" y qué contenidos desde la Didáctica apoyan este trabajo de selección de recursos, de programación de las actividades (...) Alguno ¿estuvo pensando en alguna temática, en algún contexto, en alguna situación?, porque si no resulta difícil avanzar en el trabajo, uno los puede ir asesorando, sugiriendo, orientando, pero en la medida en que a ustedes se les vayan planteando interrogantes al respecto porque si no son ideas generales que uno propone pero si ustedes todavía no han tomado ninguna decisión... son tareas que demandan bastante tiempo (...) y no es tanto el tiempo que queda por eso en la medida en que ustedes vayan demorando la decisión acerca de lo que van a trabajar... (Comunicación personal)

Feedback en relación con la tarea como producto: además de la posibilidad con que contaban los alumnos y las alumnas de acceder a su evaluación y de ver las correcciones realizadas, se advirtieron ante todas las TAA -en total 6- las sugerencias que los docentes y las docentes hacían al alumnado sobre las formas de mejorar las respuestas a las tareas solicitadas, así como los comentarios detallados que generaban acerca de las debilidades y fortalezas en las respuestas del grupo estudiantil. Al respecto, puede funcionar como ejemplo un fragmento de una devolución por escrito que le brindaron las docentes de Didáctica a un alumno en una clase, haciendo referencia al desempeño de ese alumno en una TAA; la devolución hacía referencia tanto al trabajo escrito y a la exposición oral que contemplaba la TAA, donde se le solicitaba al alumno que realizara una secuencia didáctica para una asignatura de nivel medio y, en consecuencia, este alumno había elegido el preservativo como eje de la secuencia.

Sugerencias para avanzar: profundizar la contextualización de la temática, promoviendo una visión más integral de la persona y su sexualidad que permita trascender el enfoque técnico o informativo acerca del uso del preservativo con otros tópicos complementarios.

La exposición fue clara, los argumentos esgrimidos acerca de la temática elegida resultaron adecuados aunque podría haberse profundizado la justificación didáctica de la propuesta

Calificación: 8 (ocho). (Comunicación personal)

Feedback a las estrategias: en torno a 5 de 6 TAA, se observó que se brindaba orientación y se propiciaba la reflexión sobre las estrategias de aprendizaje puestas en juego para realizar la tarea, como así también, los profesores y profesoras comentaban sobre 
estrategias personales que empleaban en la resolución de tareas similares a las propuestas en el contexto del aula. El siguiente fragmento es un ejemplo, en relación con la manera de resolver actividades requeridas por la TAA y que debían realizar los alumnos y las alumnas de Tráfico.

Docente 1 - Lo que más me interesa es que le dediquen un tiempo a manejar las herramientas, eso lo van a tener que hacer ustedes en sus casas, a manejar las herramientas, por ejemplo, el que quiera usar Python que empiece a ver cómo transmitir paquetes, cómo graficar, cómo analizar, por ejemplo, como Matlab que tiene análisis estadísticos, esas son las herramientas que vamos a usar y, el que quiera usar lenguaje de Python como herramienta use itpn (...) entonces yo les diría que vayan viendo, practicando ustedes con ese lenguaje que pretendan usar, como para que la implementación no nos lleve tanto tiempo (...). (Comunicación personal)

Feedback relativo a percepciones sobre el contexto: se identificó en relación con la posibilidad que ofrecían las consignas de todas las TAA -6- como contextos de evaluación, de realizar la evaluación tanto dentro como fuera del salón de clases y, sobre todo, el hecho de que la mayoría de las consignas de estas tareas -5 de 6 - proponían el contacto directo del alumno o de la alumna con una institución de enseñanza media o con un contexto no formal. A continuación se presenta un fragmento de clase que puede funcionar como ejemplo, del feedback generado en torno a una TAA -concretamente la TAA de Didáctica I- respecto del contexto:

Docente 1 - Por ahí toda la formación del psicopedagogo como del profesor de Enseñanza Especial, está más orientada para trabajar en los contextos formales, como que las acciones educativas tuvieran lugar exclusivamente dentro del sistema educativo, yo creo que nosotras fuimos formadas así, buena parte de nuestra formación de posgrado estuvo también orientada en ese sentido y, los planes de estudios estaban también orientados en ese sentido, no es casual, porque la Psicología Educacional se orientó en ese sentido, las disciplinas de base... la Pedagogía se orientó en ese sentido, las disciplinas de base de nuestra formación se orientaron en ese sentido; pero en este momento, acciones educativas, acciones de enseñanza, se desarrollan en muchos contextos, no sólo dentro del sistema educativo formal, entonces nosotras pensamos que es un momento importante y propicio para que ustedes puedan ir pensando su rol no sólo dentro del contexto educativo o en apoyo de lo que pasa dentro de esas instituciones formales (...) debemos abrir un poco otras perspectivas. (Comunicación personal)

Feedback relativo a aspectos de la persona: en torno a la mayoría de las TAA -5 de 6-, se apreciaron comentarios que el cuerpo docente hacía a los alumnos y a las alumnas (de manera explícita e implícita) sobre aspectos relativos a la persona, vinculados con la realización de estas tareas. A continuación se presenta como ejemplo, un fragmento de una devolución escrita brindada por las docentes de Didáctica a una alumna en relación con su 
desempeño en una TAA, orientada hacia cuestiones personales que van más allá de la tarea en sí.

La participación colaborativa en las exposiciones de los trabajos de los pares, son también representativas de actitudes solidarias y del importante compromiso con su rol de alumna. (Comunicación personal)

En cuanto a la modalidad de resolución de las consignas, todas las evaluaciones parciales tradicionales -en total 6- optaron por modalidades individuales; en cambio, todas las consignas de las TAA -en total 6- con su modalidad de resolución grupal constituyeron una buena oportunidad para el intercambio y colaboración entre pares.

El contexto de desempeño requerido por las seis evaluaciones parciales tradicionales era el aula; las 6 TAA requerían el desempeño del alumno o de la alumna tanto en el salón de clases como fuera de él (extra-clase), con los beneficios de vincularse a una institución de su futuro desempeño laboral -como ocurrió en la mayoría de las asignaturas-, ya sea: instituciones de enseñanza media, escuelas de enseñanza especial, etc.

En relación con el espacio para el despliegue de autonomía, en el caso de todos los parciales -6-, los alumnos y alumnas en general debían responder una serie de preguntas pautadas, que si bien buscaban afianzar contenidos trabajados, requerían explicaciones, comentarios y hasta ejemplos, no era posible así que los alumnos o las alumnas optasen por temáticas puntuales de su interés, sino que lo que se requería específicamente que éstos respondiesen, estaba bien pautado y delimitado. Por su parte, ante todas las TAA -6-, los alumnos y las alumnas tenían posibilidades de decidir con base en sus intereses, por ejemplo, el grupo de compañeros con los que trabajaría como así también el tema o contenido por trabajar, la modalidad de trabajo y, en los casos que así lo requerían, la institución a la que se vincularía para realizar la evaluación, es decir, el despliegue de diferentes tipos de autonomía.

Los procesos cognitivos que incluían las TAA, conformaban un abanico mucho más amplio que el de aquellos requeridos por las evaluaciones parciales, que de esta manera, promovían el despliegue de diversas habilidades por parte de los alumnos y las alumnas.

Con respecto de la promoción de procesos de autorregulación, lo observado sugiere que las consignas de los seis parciales limitaban a los alumnos y a las alumnas a regular sus aprendizajes ligados a los tiempos o modalidades de estudio y, en todo caso, a los criterios de logro y/o puntuaciones anticipados para las respuestas. En relación con las seis TAA, la libertad que se le brindaba al alumnado a través de estas consignas, favorecía las 
posibilidades de autorregulación de sus aprendizajes, es decir, regular sus propios tiempos, sus estrategias de trabajo, la elección de actividades ante las cuales sintieran más confianza, el avance en los diferentes puntos de la consigna y, además implicar la reflexión sobre estos mismos aspectos. En el mismo sentido, la anticipación de los criterios que se tendrían en cuenta para evaluar al alumno o alumna. Así, en el caso de las TAA, se promovía el control, planificación y la toma de decisiones de alumnos sobre sus propios aprendizajes.

Acerca de la percepción de instrumentalidad y significatividad, en el caso de todos los parciales, los datos sugieren que, en general, el estudiantado no percibió su utilidad para su aprendizaje y formación. Al respecto, todas las TAA se orientaban hacia el trabajo con problemas genuinos y relevantes para los alumnos y las alumnas, posibilitando aprendizajes más significativos en relación con la disciplina en cuestión y con su desempeño laboral futuro: posibilidad de generar intereses y de orientar esfuerzos para la construcción de conocimientos relacionados con situaciones más reales, integrar los contenidos del programa a entornos asociados, por ejemplo, a lo que constituirá su realidad de desempeño laboral.

Sobre la integración de la evaluación como parte del proceso de enseñanza y de aprendizaje, los parciales como evaluación tradicional estuvieron, en general, ligados a la evaluación como etapa final coartada del aprendizaje, en la que el punto de interés eran los resultados. Para las TAA, las características expuestas hasta aquí se orientan con más posibilidades de constituir modos de evaluación integrados en el proceso de aprendizaje.

Las consignas de ambos contextos evaluativos, en general -9 de 12 consignas-, presentaban claridad y organización.

\subsection{Percepciones de los alumnos y las alumnas sobre los contextos de evaluación: vinculaciones con su autoeficacia}

En relación con los contextos de evaluaciones parciales de los que participaron los alumnos y las alumnas, los comentarios de estudiantes sobre la mayoría de ellos permiten identificar percepciones con un carácter negativo -en 4 de 6 evaluaciones parciales-, ligadas a estos contextos. Por ejemplo, a pesar de que, como se menciona, todas las consignas de los parciales de estas asignaturas mantenían en general cierto nivel de claridad y organización, alumnos de Psicología Educacional comentaban sentirse "desorientados y desesperados porque no entendían alguna pregunta o porque percibían que fracasarían". A su vez, entre el grupo de estudiantes de Didáctica I -5 de 5 alumnas entrevistadas-, se 
identificaba entre los factores que influyen sobre su autoeficacia, la influencia negativa del tipo de preguntas de los parciales de Didáctica I, concretamente referido a las preguntas puntuales y estructuradas que presentaba la consigna del parcial en cuestión, así como también con un carácter negativo, la modalidad a libro abierto que presentó, ligado esto último al énfasis en el análisis más que en la memorización de los contenidos; entre las expresiones de estas alumnas: "los parciales que me hacen sentir insegura son los que tienen definiciones muy concretas (...) me da la sensación de que esperan de nosotros definiciones textuales y tampoco es favorable para un aprendizaje significativo"; "la que me hizo sentir insegura fue la del parcial de Didáctica l, que era a carpeta abierta y teníamos que hacer un análisis con los temas". Por su parte, los alumnos y alumnas de Didáctica II -6 de 8 alumnos entrevistados-, resaltaban como una influencia negativa del parcial de esta asignatura sobre su autoeficacia: la discrepancia entre qué y cómo se enseña y qué y cómo se evalúa, la extensión demasiado amplia de la consigna, la sensación de incapacidad que promovía, así como su carácter poco propicio para integrar contenidos; las siguientes expresiones de ellos como ejemplo: "por ahí se da de una forma la clase, como fácil, y el parcial fue re difícil”; "además era larguísimo, cada pregunta tenia sub-ítems, era muy largo..."; "el parcial me hizo sentir totalmente incapaz de resolver algo así"; "no sé, porque de parcial integrador no tuvo nada (...) no me pareció de relacionar". Por su parte, un grupo entre los alumnos y alumnas entrevistados de Tráfico -3 de 11 alumnos- no percibieron valor de utilidad de la modalidad de evaluación parcial de Tráfico como herramienta para su formación profesional; al respecto una de las expresiones de los alumnos era la siguiente: "En verdad yo prefiero los trabajos (...) es más rico eso... que por ahí rendir un parcial que a lo mejor es un ejercicio".

De acuerdo con lo expuesto, se advierte que estos aspectos negativos atribuidos a las evaluaciones parciales de estas asignaturas, no están ligados necesariamente a la percepción de incapacidad de los estudiantes o las estudiantes para desempeñarse en estos contextos de evaluación, lo cual podría predisponerlos a enfrentar la actividad de una manera más pesimista, sino que también estudiantes que se percibían capaces para participar en estos contextos de evaluación, señalaron factores negativos que percibieron como influyentes en su autoeficacia. Concretamente, entre los resultados obtenidos en las entrevistas semi-estructuradas con respecto a la confianza de los sujetos en sus capacidades en los momentos anteriores a las situaciones de evaluaciones parciales tradicionales, las creencias en sus capacidades se ven confirmadas en las respuestas de la mayoría de los alumnos y las alumnas entrevistadas -24 de 33 alumnos-; por ejemplo, 
comentaban: "No, sí confío en mis posibilidades sino no vendría, ni siquiera me presentaría"; "en general pienso que me va ir bien, voy confiado"; "sí, porque tengo un nivel considerable de comprensión, de memoria, de todas esas cosas". En el caso de las TAA, en general, la creencia en la capacidad para el desempeño pareciera disminuir, solo confiaban en sus capacidades para el desempeño en los momentos anteriores a las realización de estas TAA, 10 de 33 estudiantes entrevistados; al respecto, algunas de sus expresiones eran: "sentí inseguridad de no poder realizar las actividades como ellos lo pedían"; "por ahí decís jno sé si voy a ser capaz!"; etc. Sin embargo, aunque en momentos anteriores a la realización de las TAA los estudiantes y las estudiantes comentaban en las entrevistas la desconfianza en sus capacidades para realizarlas, en los momentos posteriores a la realización de estas TAA, valoraban y les atribuían solo valoraciones positivas.

Las TAA como contextos de evaluación, como ya se anticipó, aparecen vinculadas a aspectos, tales como: la autonomía que ofrece esta modalidad de evaluación al estudiante o la estudiante, ya sea en cuanto a la posibilidad de que autorregule su aprendizaje y de que elija con base en sus intereses, a su vez, el carácter innovador y creativo que estas presentaban, la posibilidad de tener esta mirada más holística en la que los contenidos de la disciplina se integren y se relacionen más abiertamente de manera más significativa e instrumental para el alumno o la alumna, la integración de la colaboración entre pares; en este sentido, se cree que este tipo de evaluaciones se integra con mayor fuerza al proceso de aprendizaje en la medida en que presenta mayor significatividad e instrumentalidad para el aprendizaje y formación del alumnado. Los comentarios de la totalidad de los estudiantes entrevistados en todas las asignaturas observadas $-\mathrm{N}=33-$, se orientan a considerar la percepción y valoración de los rasgos referidos. Así, se advierte un predominio de percepciones positivas con respecto a este tipo de contextos evaluativos, a saber: permite al alumno o alumna explayar más sus capacidades; fomenta la motivación e interés; favorece un aprendizaje más significativo; favorece la integración de conocimientos; constituye un desafío positivo; instrumentalidad; despliegue de libertad y creatividad; tarea interesante; permite percibirse como más autoeficaz; tarea innovadora; etc. Los siguientes fragmentos de las expresiones de los alumnos y las alumnas como ejemplo: "en los trabajos podíamos (...) poner nuestros puntos de vista y opiniones, en cambio en un parcial (...) no podes poner opiniones"; "es mucho más rico para mí el aprendizaje (...) te queda mucho más que haber estudiado para un parcial"; "era un desafío muy grande porque teníamos que tener en cuenta muchas cosas"; "tener la plena libertad para elegir (...) me parece que es sumamente necesario, ya que estamos en cuarto año"; "creo que es un desafío, cuando estamos 
acostumbrados a contestar cosas puntuales (...) un desafío (...) `decir bueno que hacemos, qué plateamos, desde qué base, cómo arrancamos' me parece que es mucho más productivo que venir a rendir un parcial"; "el trabajo me permitió integrar los conocimientos (...) los conocimientos que habíamos puesto en el trabajo, esos a mí me re quedaron"; "el trabajo me encantó hacerlo, es un tema que me gustó mucho"; "sí estuvo diferente"; "son métodos de evaluación distintos"; "Y tanto no hemos tenido para decir que no fue novedoso"; etc.

Asimismo, tanto con respecto a los parciales como a las TAA, se identificó entre las percepciones de estudiantes entrevistados -en 8 de 33 alumnos-, la claridad en las consignas de evaluación como un factor que afecta positivamente su aprendizaje y motivación; como expresa Vázquez (2007), la claridad es un aspecto de importancia en una consigna de evaluación. Al respecto, alumnos comentaban: "leí la consigna y estaba bien dada, bien clara y, me sentí tranquilo para realizarla"; "no solo te entregaron las consignas por escrito y ya está, sino que todas las clases te iban recalcando algo o ibas preguntando dudas".

\section{Discusión de resultados y conclusiones}

Entre los resultados de este trabajo, se advierte una vinculación entre las características del contexto de evaluación diseñado, las creencias de autoeficacia que sustentan los alumnos y las alumnas y los resultados académicos obtenidos.

Las percepciones de estudiantes en las entrevistas semi-estructuradas pareciera que, en primera instancia, no coincidieran con la teoría, ya que mientras los estudiantes y las estudiantes se percibían capaces en los momentos anteriores a las evaluaciones parciales, en los momentos posteriores a la realización de estas evaluaciones, les atribuían valoraciones negativas; por lo contrario, mientras que comentaban en las entrevistas la desconfianza en sus capacidades en momentos anteriores a la realización de las TAA, en los momentos posteriores a la realización de estas TAA, valoraban y les atribuían solo valoraciones positivas.

Estos resultados, se considera que podrían atribuirse a un cambio en la percepción de alumnos y alumnas sobre el contexto de evaluación, en función de la experiencia, es decir, mediados por su participación en estos contextos evaluativos. Esto se debe, probablemente, a que estos contextos de evaluación (parcial tradicional y TAA) conformaban contextos distintos, y no que se deba a la presencia de un contexto de evaluación poco propicio, sino, 
más bien, a los temores que implicaba presentarse ante una modalidad de evaluación distinta a lo que estaban acostumbrados; esto estaría vinculado con la fuente de autoeficacia referida a los logros de ejecución -Bandura, 1987, 1999-, que involucra experiencias de dominio real por parte del o la estudiante. Si se considera que las TAA conformaban un contexto de evaluación que no era habitual en el ámbito universitario, sería entendible que estos estudiantes dudaran de sus capacidades para desempeñarse ante estas. Según los datos que arrojan las entrevistas, las TAA fueron caracterizadas por los propios alumnos y las alumnas por ser un contexto novedoso, "diferente", un "desafío", a la vez que lo identificaron positivamente como modalidad o tarea "innovadora" de evaluación. En otras palabras, habría que considerar que este grupo de alumnos en general, como manifestaban en las entrevistas, no había participado antes en este tipo de contexto de evaluación que conforma la TAA y, por lo tanto, no tenían experiencia en tal dominio para haber generado autoeficacia positiva, por ello la desconfianza a enfrentarse a algo que es nuevo para ellos.

De allí la importancia de las experiencias previas como fuente de autoeficacia para estudiantes, es decir, de ofrecer experiencias de dominio a estudiantes ante aquellas actividades, comportamientos estratégicos, manejos de recursos para el aprendizaje, entre otros, para los cuales pudieran percibir autoeficacia disminuida. De hecho, luego de participar en las TAA, se advierte que los estudiantes y las estudiantes les otorgaban valoraciones positivas, incluso, entre ellas, la posibilidad de esta modalidad de contexto evaluativo de incrementar sus capacidades, además del mayor interés y percepción de utilidad que atribuían a esta modalidad de evaluación. A su vez, el rendimiento académico que obtuvieron en este contexto evaluativo, en general, fue óptimo.

Por su parte, los contextos de evaluación parcial resultaban más tradicionales para el alumno y la alumna, sugeriríamos que se percibían más cómodos ante este tipo de evaluación porque es lo que están acostumbrados a hacer, sin embargo, no fueron pocos los comentarios sobre sus percepciones con un carácter negativo con respecto a esta modalidad de evaluación, como así también el rendimiento académico obtenido, en general, fue más bajo para estos contextos evaluativos.

Así, se llega a la conclusión de que los contextos de evaluación influyen sobre las creencias de autoeficacia y el rendimiento académico de estudiantes y viceversa.

Se advierte los beneficios para la motivación y el aprendizaje de estudiantes universitarios, de aquellos contextos evaluativos que escaparon a las modalidades más tradicionales, como en este caso fueron las TAA, así como también, que la participación en 
uno $u$ otro contexto evaluativo no es indiferente para el estudiantado, sino que tiene influencias sobre su motivación, como se suponía, en su autoeficacia y rendimiento.

Es decir, como sostiene la teoría, hay una dependencia de los juicios de autoeficacia del contexto específico de funcionamiento en el que se encuentra inserto el sujeto -Bandura, 1987, 2005; Pajares, 2001; Schunk y Meece, 2005; Zimmerman, 1999; entre otros-.

Particularmente a través de la realización de este trabajo, se puede sugerir que hay una dependencia entre el contexto específico de evaluación en el que participan estudiantes universitarios, su autoeficacia y rendimiento académico. Precisamente, se considera que aquellos estudiantes, quienes participan en contextos evaluativos más ricos, verían incrementadas sus posibilidades de desarrollar, modificar y potenciar la confianza en sus capacidades para el desempeño, así como de obtener un mejor rendimiento, que a su vez, influiría en su autoeficacia. Al respecto, se debe recordar que la teoría plantea el carácter dinámico de estas creencias en relación con el contexto, así como la posibilidad de ser desarrolladas -Bandura 1987, 1999; Ruiz Dodobara, 2005-. Por ejemplo en el caso de las TAA que se brindaron en este estudio, se cree que la autoeficacia para el desempeño tiene mayores posibilidades de ser desarrollada, en relación con el contenido específico de una asignatura particular, pero también en relación con otros aspectos como la participación en un contexto evaluativo diferente que les puede resultar más desafiante y, en algunos casos, también en relación con desplegar el contacto con lo que será su futuro campo de desempeño laboral.

Revisando trabajos empíricos actuales que se hayan abocado a la autoeficacia de acuerdo con el aprendizaje, se advierten en general muchos trabajos -Barca Enríquez, Vicente Castro, Almeida y Barca Lozano, 2014; Hernández Jácques y Barraza Macías, 2014; Barca Lozano, Almeida, Porto-Rioboo, Peralbo Uzquiano y Brenlla Blanco, 2012; Pool Cibrián y Martínez Guerrero, 2013; etc.- que han estudiado la autoeficacia según la autorregulación académica, con el uso de estrategias, el rendimiento académico, metas de aprendizaje, etc.; otros trabajos atienden la relación entre autoeficacia y contextos de aprendizaje, por ejemplo el de Cummings Swingle y Vieta (2012), quienes se interesan por conocer si la autoeficacia es válida como predictora del éxito académico en contextos de formación virtual. No obstante, como se anticipaba, no se encontró trabajos que puedan hacer algún aporte con respecto de la autoeficacia vinculada a los contextos de evaluación, como es el caso de este trabajo.

Cabe aclarar que la intención de ese trabajo no es hablar de la superioridad de una modalidad de evaluación sobre otra; de hecho, la misma teoría -Camilloni et al., 1998; 
Ravela, 2006- sugiere que no hay modalidades de evaluación que sean mejores que otras, sino que esto dependerá de la pertinencia de esa modalidad de evaluación con el objeto evaluado, con los sujetos implicados y el contexto; por este motivo, se cree que como decentes se debe comprender que existen contextos evaluativos poderosos y que permiten potenciar, desarrollar y/o modificar, en este caso, creencias motivacionales en estudiantes en beneficio de su aprendizaje y rendimiento. Por ello, no se piensa que deba abandonarse la modalidad de evaluación parcial más de tipo tradicional y mucho menos desvalorizar sus aportes para el aprendizaje, pero sí promover otras propuestas superadoras, creativas y con muchas posibilidades para evaluar, que tengan cuidado también sobre la motivación y el rendimiento del alumno o de la alumna. Esto se lo plantea desde la perspectiva de que los mismos estudiantes comentaban entre sus percepciones los beneficios a favor, en este caso, de las TAA como modalidad de evaluación; aspecto que se cree no puede pasar desapercibido.

De acuerdo con lo expuesto hasta aquí, se podría sintetizar lo siguiente: 1) los alumnos y las alumnas no fueron indiferentes a la participación en uno u otro contexto de evaluación en los que se desempeñaron en este estudio -parcial o TAA- y en relación con los que participan habitualmente en el ámbito universitario en general; 2) hubo diferencia en cuanto a sus creencias de autoeficacia, a sus percepciones, valoraciones y rendimiento sobre uno $u$ otro contexto, que hablan a favor de los beneficios de participar en un contexto evaluativo más poderoso, como se considera en este caso a la TAA; 3 ) en este sentido, se piensa que hay una vinculación entre las creencias de autoeficacia de estudiantes, la participación en los diferentes contextos evaluativos y el rendimiento académico.

Desde esta perspectiva, algunas implicaciones prácticas de los resultados de este estudio para el ejercicio docente podrían ser las siguientes:

- Hacer todos los esfuerzos por incorporar a la evaluación como parte del aprendizaje. Llevar a la práctica planteos en los que se centran trabajos más actuales, ligados a repensar la evaluación "para" el aprendizaje; en otras palabras, fundamentar y desarrollar modelos de evaluación que mejoren la motivación y el aprendizaje (Álvarez Méndez, 2012; Litwin, 2008).

- Transformar a la evaluación en una herramienta poderosa para desarrollar la confianza de estudiantes para con sus desempeños. Como sostiene Celman (2007), los docentes y las docentes tienen la responsabilidad reflexionar sobre el carácter complejo de las problemáticas educativas. Creemos que la reflexión que se debe hacer como docentes es que los alumnos y las alumnas están aprendiendo y que aprender implica equivocarse, interactuar, hacer y observar, no solo responder preguntas memorísticamente frente a una 
hoja en blanco. Al respecto, se sugiere que, por ejemplo, los contextos de evaluación de alcances amplios, como se brindaron en este estudio, permiten aumentar las posibilidades de que el estudiante o la estudiante incorpore a la evaluación como una instancia más de aprendizaje.

- Incorporar cotidianamente el feedback. Es el feedback lo que según Celman (2007) "deja abierto el proceso para el reaprendizaje". Y en este sentido creemos que también puede ser un interesante camino para incorporar a la evaluación, dándole continuidad como parte del aprendizaje.

En relación con lo expuesto en este estudio y con los resultados obtenidos, las siguientes podrían constituirse en inquietudes que confluyan hacia futuras líneas de investigación: Profundizar en la autoeficacia vinculada específicamente a la explicitación de los criterios de evaluación; es decir, la autoeficacia en estudiantes ante instancias evaluativas en las que se construyeran abierta y reflexivamente, docente-alumno, los criterios de evaluación, en comparación con otras instancias en las que los criterios estuvieran ausentes. Indagar la vinculación o el impacto de la claridad de las consignas de evaluación sobre la autoeficacia de estudiantes podría resultar interesante siendo que no se encontraron trabajos empíricos al respecto.

\section{Referencias}

Alonso Tapia, Jesús. (2000). Motivar para el aprendizaje. Teorías y estrategias. Barcelona: Edebé.

Álvarez Méndez, Jesús Manuel. (2000). Didáctica currículum y evaluación. Ensayos sobre cuestiones didácticas. Buenos Aires: Miño y Dávila.

Álvarez Méndez, Jesús Manuel. (2012). Pensar la evaluación como recurso de aprendizaje. En Beatriz Jarauta y Francisco Imbernón (Coords.), Pensando en el futuro de la educación; una nueva escuela para el siglo XXII (pp. 139-158). Barcelona: Graó.

Bandura, Albert. (1987). Pensamiento y acción. Fundamentos sociales. Barcelona: Martínez Roca.

Bandura, Albert. (1994). Self-efficacy. En Ramachaudran, V. S. (Ed.), Enciclopedia de la Conducta Humana, (Vol. 4, pp. 71-81). Recuperado de http://www.uky.edu/ eushe2/Bandura/BanEncy.html

Bandura, Albert. (1999). Auto-eficacia: Cómo afrontamos los cambios de la sociedad actual. Bilbao: Desclée de Brouwer. 
Bandura, Albert. (2005). Adolescent development from an agentic perspective. En Frank Pajares y Tim Urdan (Eds.), Self-efficacy beliefs of adolescents (pp. 1-43). Recuperado de http://www.uky.edu/ eushe2/Bandura/001-BanduraAdoEd2006.pdf

Barca Enríquez, Eduardo., Vicente Castro, Florencio., Almeida, Leandro y Barca Lozano, Alfonso. (2014). Impacto de estrategias de aprendizaje, autoeficacia y género en el rendimiento del alumnado de educación secundaria. International Journal of Developmental and Educational Psychology, 2(1), 287-297. Recuperado de http://dehesa.unex.es/xmlui/bitstream/handle/10662/1974/0214-

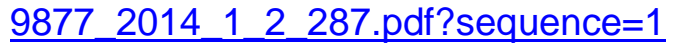

Barca Lozano, Alfonso, Almeida, Leandro, Porto-Rioboo, Ana María, Peralbo Uzquiano, Manuel y Brenlla Blanco, Juan. (2012). Motivación escolar y rendimiento: impacto de metas académicas, de estrategias de aprendizaje y autoeficacia. Anales de Psicología, 28(3), 848-859. Recuperado de http://www.redalyc.org/articulo.oa?id=16723774023

Bloom, Benjamin, Hastings, Thomas y Madaus, George. (1975). Evaluación del aprendizaje. Buenos Aires: Troquel.

Bong, Mimi. (2004). Academic motivation in self efficacy, task value, achievement goal orientations, and attributional beliefs. The Journal of Educational Research, 97(6), 287298.

Camilloni, Alicia, Celman, Susana, Litwin, Edith y Palou de Maté, María del Carmen. (1998). La evaluación de los aprendizajes en el debate didáctico contemporáneo. Buenos Aires: Paidós.

Carrasco, Miguel Ángel y del Barrio, María Victoria. (2002). Evaluación de la autoeficacia en niños y adolescentes. Psicothema, 14(2), 323-332. Recuperado de http://www.unioviedo.net/reunido/index.php/PST/article/view/8022/7886

Celman, Susana. (2007). Evaluación de los aprendizajes universitarios más allá de la acreditación. Colección de Cuadernillos de actualización para pensar la Enseñanza Universitaria, (11), 1-24.

Coll, César y Onrubia, Javier. (2002). Evaluar en una escuela para todos. Cuadernos de Pedagogía, 50(318), 50-54. Recuperado de http://www.psyed.edu.es/prodGrintie/articulos/CC JO EvaluarEscuelaTodos 02.pdf

Coll, César, Rochera Villach, María José, Mayordomo Saíz, Rosa María y Naranjo Llanos, Mila. (2007). Evaluación continua y ayuda al aprendizaje. Análisis de una experiencia de innovación en educación superior con el apoyo de las TIC. Revista Electrónica de Investigación Psicoeducativa, 5(13), 783-804. Recuperado de http://www.investigacionpsicopedagogica.org/revista/articulos/13/espannol/Art 13 205.pdf

Creswell, John y Plano Clark, Vicki. (2007). Designing and Conducing Mixed Methods Research. London: SAGE Publications.

Cummings Swingle, Nydia y Vieta, Vivian. (2012). Is the online generation ready for online learning? A study of online technologies self-efficacy perceptions as predictors of academic success in virtual education programs. Revista Complutense de Educción, 
23(1), 135-147. Recuperado de http://revistas.ucm.es/index.php/RCED/article/viewFile/39106/37719

Cupani, Marcos y Pérez, Edgardo Raúl. (2006). Metas de elección de carrera: Contribución de los intereses vocacionales, la autoeficacia y los rasgos de personalidad. Revista Interdisciplinaria, 23(1), 81-100. Recuperado de http://www.scielo.org.ar/scielo.php?pid=S1668-70272006000100005\&script=sci arttext

Donolo, Danilo Silvio, Chiecher, Analía, Paoloni, Paola Verónica y Rinaudo, María Cristina. (2008). MSLQe -MSLQw. Motivated Strategies Learning Questionnaire. Propuestas para la medición de la motivación y el uso de estrategias de aprendizaje. Río Cuarto: Editorial de la Fundación Universidad Nacional de Río Cuarto.

González Fernández, Antonio. (2005). Motivación académica. Teoría, aplicación y evaluación. Madrid: Pirámide.

González Pérez, Miriam. (2000). Evaluación del aprendizaje en la enseñanza universitaria. Revista Pedagogía Universitaria, 5(2), 31-61. Recuperado de http://fagro2.fagro.edu.uy/docs/uensenia/Gonaz\%C3\%A1lez \%20Fines\%20de\%20la\% 20Evaluaci\%C3\%B3n.pdf

Greene, Bárbara. (2004). Predicting high school students' cognitive engagement and achievement: contributions of classroom perceptions and motivation. Contemporary Educational Psychology, 29(4), 462-482.

Hattie, John and Timperley, Helen. (2007). The power of feedback. Review of Educational Research, 77(1), 81-112. Recuperado de http://education.qld.gov.au/staff/development/performance/resources/readings/powerfeedback.pdf

Huertas, Juan Antonio. (1997). Motivación. Querer aprender. Buenos Aires: Aique.

Ibarra, María Soledad, Rodríguez, Gregorio y Gómez, Miguel Ángel. (2012). La evaluación entre iguales: beneficios y estrategias para su práctica en la universidad. Revista de Educación, (359), 206-231. Recuperado de http://www.revistaeducacion.mec.es/doi/359 092.pdf

Litwin, Edith. (1998). La evaluación: campo de controversias y paradojas o un nuevo lugar para la buena enseñanza. En Alicia Camilloni, Susana Celman, Edith Litwin, y María del Carmen Palou de Maté (Eds.), La evaluación de los aprendizajes en el debate didáctico contemporáneo (pp. 11-34). Buenos Aires: Paidós.

López Frías, Blanca Silvia e Hinojosa, Kleen, Elsa María. (2000). Evaluación del aprendizaje. México: Trillas.

Mateo, Joan Andrés. (2000). La evaluación educativa, su práctica y otras metáforas. Barcelona: ICE-Horsori.

Monereo, Carles y Pozo, Juan Ignacio. (2003). La universidad ante la nueva cultura educativa. Barcelona: Síntesis. 
Olaz, Fabián Orlando. (2001). La teoría social cognitiva de la autoeficacia. Contribuciones a la explicación del comportamiento vocacional (Tesis de licenciatura en Psicología). Universidad Nacional de Córdoba, Argentina. Recuperado de http://www.uky.edu/ eushe2/Pajares/olaz.pdf

Pajares, Frank. (2001). Current directions in self-efficacy research. In Maehr, M. and Pintrich, P. R. (Eds.), Advances in motivation and achievement 10 (pp.1-49). Recuperado de http://www.uky.edu/ eushe2/Pajares/effchapter.html

Pajares, Frank. (2002). Sel-efficacy beliefs in academic contexts: an outline. Recuperado de: http://www.uky.edu/ eushe2/Pajares/efftalk.html

Pajares, Frank and Schunk, Dale. (2001). Self-beliefs and school success: self-efficacy, selfconcept, and school achievement. En Richard Riding and Stephen Rayner. (Eds.), Perception (pp. 239-266). London: Abelx Publishing.

Paoloni, Paola Verónica y Rinaudo, María Cristina. (2014). Los procesos de feedback desde una perspectiva multidimensional. Un estudio orientado a promover autorregulación en estudiantes universitarios. En Paola Verónica Paoloni, María Cristina Rinaudo y Antonio González Fernández (Comps.), Cuestiones en Psicología Educacional. Perspectivas teóricas, metodológicas y estudios de campo (pp. 287-324). Río Cuarto: Cuadernos de Educación / 01, Universidad Nacional de Río Cuarto.

Paoloni, Paola Verónica, Rinaudo, María Cristina, Donolo, Danilo Silvio y Chiecher, Analía. (2006). Motivación. Aportes para su estudio en contextos académicos. Río Cuarto: Editorial de la Fundación Universidad Nacional de Río Cuarto

Pérez, Edgardo Raúl y Cupani, Marcos. (2008). Validación del inventario de autoeficacia para inteligencias múltiples revisado (IAMI-R). Revista Latinoamericana de Psicología, 40(1), 47-58. Recuperado de http://www.scielo.org.co/scielo.php?pid=S0120$\underline{05342008000100004 \& \text { script=sci arttext }}$

Pintrich, Paul, Smith, David, García, Teresa and Mckeachie, Wilbert. (1991). A manual for the use of the Motivated Strategies for Learning Questionnaire (MSLQ). Recuperado de http://files.eric.ed.gov/fulltext/ED338122.pdf

Pool Cibrián, Wilson Jesús y Martínez Guerrero, José. (2013). Autoeficacia y uso de estrategias para el aprendizaje autorregulado en estudiantes universitarios. Revista Electrónica de Investigación Educativa, 15(3), 21-37. Recuperado de http://www.redalyc.org/articulo.oa?id=15529662002

Ravela, Pedro. (2006). Para comprender las evaluaciones educativas. Fichas Didácticas (Grupo de trabajo sobre estándares y evaluación). Perú: Programa de Promoción de la Reforma Educativa en América Latina. Recuperado de http://www.upn303.com/files/Fichas-didacticas-comprender-evaluacioneseducativas.pdf

Rinaudo, María Cristina. (2014). Estudios sobre contextos de aprendizaje: arenas y fronteras. En Paoloni, Paola Verónica, Rinaudo, María Cristina y González Fernández, Antonio. (Comps.), Cuestiones en Psicología Educacional. Perspectivas teóricas, metodológicas 
y estudios de campo (pp. 163-206). Río Cuarto: Cuadernos de Educación / 01, Universidad Nacional de Río Cuarto.

Rinaudo, María Cristina y Paoloni, Paola Verónica. (2013). Feedback en los aprendizajes. Potencialidad de los entornos virtuales. En Chiecher, Analía, Donolo, Danilo Silvio y Corica, José Luis. (Eds.), Entornos virtuales y aprendizaje. Nuevas perspectivas de estudio e investigaciones (pp. 95-133). Mendoza: Virtual Argentina.

Rochera Villach, María José y Naranjo Llanos, Mila. (2007). Ayudar a autorregular el aprendizaje en una situación de evaluación. Revista Electrónica de Investigación Psicoeducativa, 5(13), 805-824. Recuperado de http://www.investigacionpsicopedagogica.org/revista/articulos/13/espannol/Art 13 147.pdf

Rodríguez Conde, María José y Jiménez Corrales, Rafael Esteban. (2010). Evaluación de aprendizajes en e-learning. En Nieto Martín, Santiago y Rodríguez Conde, María José. (Coords.), Investigación y Evaluación Educativa en la Sociedad del Conocimiento (pp. 53-80). Salamanca: Ediciones Universidad de Salamanca.

Ruiz Dodobara, Fernando. (2005). Influencia de la autoeficacia en el ámbito académico. Revista Docencia Universitaria., (1), 1-16. Recuperado de http://info.upc.edu.pe/hemeroteca/Publicaciones/Art2 FR.pdf

Ruiz de Pinto, Laura. (2002). Evaluación-Tipos de evaluación. Revista de Posgrado de la Vla Cátedra de Medicina, (118). Recuperado de http://med.unne.edu.ar/revista/revista118/evaluacion.html

Schunk, Dale. (1984). Self-efficacy perspective on achievement behavior. Educational Psychologist, $19, \quad 48-58 . \quad$ Recuperado de https://libres.uncg.edu/ir/uncg/f/D Schunk Self 1984.pdf

Schunk, Dale and Meece, Judith. (2005). Self-efficacy development in adolescences. En Frank Pajares and Tim Urdan. (Eds.), Self-efficacy beliefs of adolescents (pp. 71-96). Greenwich, CT: Information Age Publishing.

Taymal Ortega, Ingrid Johann. (2008). El papel de la autoeficacia en el aprendizaje. Recuperado de http://revistavarela.uclv.edu.cu/articulos/rv1103.pdf

Villardón Gallego, Lourdes. (2006). Evaluación del aprendizaje para promover el desarrollo de competencias. Revista de la Facultad de Educación, 1(24), 57-76. Recuperado de http://revistas.um.es/index.php/educatio/article/viewFile/153/136

Zimmerman, Barry John. (1999). Autoeficacia y desarrollo educativo. En Albert Bandura (Ed.), Auto-eficacia: cómo afrontamos los cambios de la sociedad actual (pp. 177-200). Bilbao: Desclée de Brouwer.

Zimmerman, Barry John and Cleary, Timothy. (2006). Adolescents' development of personal agency. The role of self-efficacy beliefs and self-regulatory skill. En Frank Pajares and Tim Urdan (Eds.), Self-efficacy beliefs of adolescents (pp. 45-70). Greenwich, CT: Information Age Publishing. 